\title{
Characteristics of Feeding Practices and Nutritional Status of Infants in Selected Villages at Dhamrai
}

\author{
Farah $\mathrm{S}^{1}$, Karim $\mathrm{M}^{1}$ \\ ${ }^{1}$ Department of Community Medicine, Dhaka Community Medical College, Moghbazar, Dhaka-1217 \\ Email: shayelafarah@yahoo.com
}

\begin{abstract}
Infants are the most vulnerable group among all the age groups in our society. Breastfeeding decisions and practices are influenced by multiple factors including knowledge, attitude and beliefs. This rural based cross sectional descriptive study carried out among 320 mothers having infant up to 1 year of selected villages at Dhamrai from 7th August to 31th January 2014, to determine the characteristics of feeding practices and nutritional status of infants. Near fifty percent infants belonged to age group 9-12 months and of them one third were more than $8 \mathrm{~kg}$. Regarding feeding status $284(88.8 \%)$ of respondents got colostrum's bit about fifty-five percent mother did not know the benefit of exclusive breastfeeding. The observation regarding complementary feeding $142(50.9 \%)$ infants were started after six months of age and the common types of complementary food were khichuri (49.7\%), shagu, suji $(21.5 \%)$, fruit juice $(6.8 \%)$ given as family food. It was found that $208(65 \%)$ mothers were encouraged by doctors to practice weaning food. The prevalence of severe underweight and moderate underweight in the studied children were $10.9 \%$ and $14.1 \%$ respectively, the prevalence of moderate and severe wasting children was $6.2 \%$ and $3.2 \%$ respectively and the prevalence of severely and moderately stunted children were $8.3 \%$ and $10.9 \%$ respectively. Proper breastfeeding practices are effective ways for reducing infant morbidity and mortality. So it may be concluded that correct breast feeding practices should be supported and promoted to improve the well-being of infants.
\end{abstract}

Key words: Exclusive breast feeding, complementary feeding, colostrums, weaning.

\section{Introduction}

Exclusive breastfeeding can be defined as a practice whereby the infants receive only breast milk and not even water, other liquids, tea, herbal preparations, or food during the first six months of life, with the exception of vitamins, mineral supplements, or medicines. ${ }^{1}$ The major advantage of exclusive breastfeeding up to four to six months includes reduced morbidity due to gastrointestinal infection. The World Health Organization (WHO) recommends that infants be exclusively breastfed for the first six months, followed by breastfeeding along with complementary foods for up to two years of age or beyond. ${ }^{2}$ Delayed breastfeeding initiation, colostrum deprivation, supplementary feeding of breast milk substitutes, early introduction of complementary feeding, and incorrect weaning from breast milk are commonly found practices in communities around the world. ${ }^{3-7}$ Adequate nutrition during infancy and early childhood is essential to ensure the growth, health, and development of children to their full potential. ${ }^{8}$ It has been recognized worldwide that breastfeeding is beneficial for both the mother and child, as breast milk is considered the best source of nutrition for an infant. ${ }^{9}$ A meta-analysis from three developing countries showed that infants who were not breastfed had a six-fold greater risk of dying from infectious diseases within the first two months of life than those who were breastfed. ${ }^{10}$ Six months of exclusive breastfeeding and continued breastfeeding in the first year of life could also prevent 1.3 million child deaths worldwide according to systematic reviews from the Bellagio Child Survival Study Group. The 
timely introduction of complementary feeding can prevent almost $6 \%$ of under-five mortality. ${ }^{11}$ In addition, incorrect infant feeding practices pose significant risk for malnutrition among children under the age of five.,12,13 To achieve the Millennium Development Goals (MDG 4) for child survival and the prevention of malnutrition (MDG 3), adequate nutrition and health during the first several years of life is fundamental. ${ }^{14}$ Proper feeding practice is the cornerstones of the care for infants and young children. ${ }^{15}$ Predictors of breastfeeding and weaning practices vary between and within countries. Urban or rural difference, age, breast problems, societal barriers, insufficient support from family, knowledge about good breastfeeding practices, mode of delivery, health system practices, and community beliefs have all been found to influence breastfeeding in different areas of developing countries.,16,17 In Bangladesh, the prevalence of feeding practices has remained largely unchanged for nearly two decades. It was around 45\% in 1993-94 and 1999$2000,{ }^{18-19}$ then declined to $42 \%$ in $2004^{20}$ and was $43 \%$ in $2007 .{ }^{21}$ However, in 2011, a prevalence of $64 \%$ was reported, an increase of $21 \%$ points. ${ }^{22}$ In Bangladesh, health planners and health managers need continuous, up-dated data on infant wellbeing to reduce morbidity and mortality of this highly critical, vulnerable age segment of the population. Thus for greater understanding and addressing the issue further, the present study was conducted in a rural setting with the aim to determine the characteristics and nutritional status of infants.

\section{Materials and Methods}

This was a community based cross sectional study to determine the characteristics of feeding practices and nutritional status of infants in selected villages, at Dhamrai conducted from August to January, 2014. A total of 320 children were selected conveniently for the study. The sample was selected from Dautia, Barachandra, Kalampur villages of Dhamrai where the lactating mothers who had baby up to one year were included as the study population. Those who were aged one year and above, severely sick children, mothers requiring hospitalization and motherless children were excluded from the study. A structured pre-tested questionnaire was developed consisting of two parts- socio-demographic characteristics and feeding related variables. Face to face interview technique was used to collect data. The collected data were checked, verified and then entered into the computer. Only the fully completed questionnaire was entered into the computer for final analysis with the help of SPSS (Statistical Package of Social Science, version17), Windows software program.

\section{Result}

It was found that $261(81.5 \%)$ of the respondents were from the age group 20-30 years with mean age was $25.34 \pm 4.281$.

Table I: Socioeconomic characteristic

\begin{tabular}{|c|c|c|}
\hline $\begin{array}{l}\text { Socioeconomic characteristics } \\
\text { of the mothers }\end{array}$ & Frequency & $\begin{array}{l}\text { Percent } \\
(\%)\end{array}$ \\
\hline \multicolumn{3}{|l|}{ Age } \\
\hline$<20$ years & 33 & 10.3 \\
\hline 20-30 years & 261 & 81.5 \\
\hline$>30$ years & 26 & 08.1 \\
\hline \multicolumn{3}{|l|}{ Mean=25.34,SD=( $( \pm) 4.281$} \\
\hline \multicolumn{3}{|l|}{ Education } \\
\hline Illiterate & 71 & 22.2 \\
\hline Primary & 151 & 47.2 \\
\hline Secondary & 96 & 30.0 \\
\hline Higher secondary \& above & 02 & 0.6 \\
\hline \multicolumn{3}{|l|}{ Occupation } \\
\hline House wife & 301 & 94.1 \\
\hline Farmer & 05 & 1.6 \\
\hline Service holder & 14 & 4.4 \\
\hline \multicolumn{3}{|l|}{ Monthly family income } \\
\hline Taka $<5000$ & 132 & 41.3 \\
\hline Taka 5000-10000 & 149 & 46.6 \\
\hline Taka $>10000$ & 39 & 12.2 \\
\hline \multicolumn{3}{|l|}{ Mean=7626.56,SD $=( \pm) 3171.25 \mathrm{Tk}$} \\
\hline \multicolumn{3}{|l|}{ Type of family } \\
\hline Nuclear & 190 & 59.4 \\
\hline Joint family & 130 & 40.6 \\
\hline \multicolumn{3}{|l|}{ BMI (Mother) } \\
\hline$<18.5$ & 75 & 23.4 \\
\hline$>18.5$ & 245 & 76.5 \\
\hline
\end{tabular}

Table I: Near fifty percent of the respondents were educated up to primary level. According to the occupational status majority 301(94.1\%) participants were housewives. The mean monthly family income of the respondents was $7626.56 \pm 3171.248$ Taka. Most 190(59.4\%) of the respondents were nuclear family and $130(40.6 \%)$ belongs to joint family. About 75 (23.4\%) of the mothers' BMI were $<18.5$ which is the cut off value for chronic energy deficiency/maternal malnutrition. (Table I) Regarding characteristics 
of the infants $169(52.8 \%)$ were male and $151(47.2 \%)$ were female. Out of 320 respondents $137(42.8 \%)$ belongs to age group 9-12 months, among others $124(38.8 \%), 59(18.4 \%)$ of the respondents were 6-9 months and less than six month of age group respectively. Near about one third were more than $8 \mathrm{~kg}$ and 95(29.7\%) were 6$8 \mathrm{~kg}$ and 53(16.6\%) were less than $4 \mathrm{~kg}$.

Table II: Characteristics of infant $(n=320)$

\begin{tabular}{|c|c|c|}
\hline $\begin{array}{l}\text { Characteristics } \\
\text { of the respondents(infant) }\end{array}$ & Frequency & $\begin{array}{l}\text { Percent } \\
(\%)\end{array}$ \\
\hline \multicolumn{3}{|l|}{ Sex } \\
\hline Male & 169 & 52.8 \\
\hline Female & 151 & 47.2 \\
\hline \multicolumn{3}{|l|}{ Age of infant } \\
\hline$<6$ months & 59 & 18.4 \\
\hline 6-9 months & 124 & 38.8 \\
\hline 9-12 months & 137 & 42.8 \\
\hline \multicolumn{3}{|l|}{ Mean=8.44, $\mathrm{SD}=( \pm) 3.082$} \\
\hline \multicolumn{3}{|l|}{ Weight of infant } \\
\hline$<4 \mathrm{~kg}$ & 53 & 16.6 \\
\hline $4-6 \mathrm{~kg}$ & 76 & 23.8 \\
\hline $6-8 \mathrm{~kg}$ & 95 & 29.7 \\
\hline$>8 \mathrm{~kg}$ & 96 & 30.0 \\
\hline
\end{tabular}

(Table II) According feeding status 284(88.8\%) of the respondents were getting colostrums and the rest $36(11.3 \%)$ did not due to ignorance 20(55.5\%), illness $07(19.4 \%)$ and insufficient breast milk. The observation regarding complementary feeding $142(50.9 \%)$ respondents were started after six months of age and only $27(9.7 \%)$ started at four months of age. The common types of complementary food were khichuri (49.7\%), shagu, suji (21.5\%), fruit juice $(6.8 \%)$ given as family food. It was found that $208(65 \%)$ mothers were encouraged by doctors to practice weaning food for children, while $64(20 \%)$ encouraged by their relatives.

(Table III) The prevalence of severe underweight and moderate underweight in the studied children were $10.9 \%$ and $14.1 \%$ respectively, the prevalence of moderate and severe wasting children was $6.2 \%$ and $3.2 \%$ respectively and the prevalence of severely and moderately stunted children were $8.3 \%$ and $10.9 \%$ respectively.
Table III: Feeding status of infants $(n=320)$

\begin{tabular}{lcc}
\hline & Frequency & Percent (\%) \\
\hline Colostrums & & \\
Given & 284 & 88.8 \\
Not given & 36 & 11.3 \\
Reasons for not getting & & \\
EBF & 20 & 55.5 \\
Ignorance & 07 & 19.4 \\
Illness of mother & 09 & 25.0 \\
Insufficient of breast milk & & \\
Time of introduce of & & \\
complementary feeding & & \\
4 months & 27 & 9.7 \\
5 months & 35 & 12.5 \\
6 months & 75 & 26.9 \\
$>6$ months & 142 & 50.9 \\
Types of complementary & & \\
food & & 49.7 \\
Solid food (Khichuri) & 92 & 21.5 \\
Semisolid food (Shagu, suji) & 47 & 6.8 \\
Liquid (Fruit juice) & 15 & \\
Information about the use & & \\
of weaning food & & \\
Doctor & 208 & 65.0 \\
Relative & 64 & 20.0 \\
Neighbor & 26 & 7.9 \\
Radio/Television & 14 & 4.5 \\
Others & 08 & 2.6 \\
\hline
\end{tabular}

Table IV: Growth and development of infant

\begin{tabular}{|c|c|c|c|c|c|c|}
\hline & \multicolumn{2}{|c|}{ Weight for age } & \multicolumn{2}{|c|}{ Weight for height } & \multicolumn{2}{|c|}{ Height for age } \\
\hline & Freq. & $\%$ & Freq. & $\%$ & Freq. & $\%$ \\
\hline Normal & 240 & 75 & 290 & 90.6 & 258 & 80.8 \\
\hline $\begin{array}{l}\text { Moderate } \\
\text { (Z score- } \\
3 \text { to-2.01) }\end{array}$ & 45 & 14.1 & 20 & 6.2 & 35 & 10.9 \\
\hline $\begin{array}{l}\text { Severe } \\
(Z \text { score }<-3)\end{array}$ & 35 & $\begin{array}{c}10 . \\
9\end{array}$ & 10 & 3.2 & 27 & 8.3 \\
\hline Total & 320 & 100 & 320 & 100 & 320 & 100 \\
\hline
\end{tabular}

Table V: Logistic regression independent variables on dependent variable (Sufficient breast feeding)

\begin{tabular}{lccccc}
\hline \multicolumn{1}{c}{ Variables } & B & S.E. & Wald & Sig. & $\operatorname{Exp(B)}$ \\
\hline $\begin{array}{l}\text { Monthly income } \\
\text { Type of family }\end{array}$ & .000 & .000 & .174 & .676 & 1.000 \\
Nuclear family & -.013 & 41599.857 & .000 & 1.000 & .987 \\
Extended family & -1.063 & 41599.857 & .000 & 1.000 & .345 \\
Occupation & & & 2.676 & .262 & \\
Housewife & 19.091 & 10728.109 & .000 & .999 & $1.955 \mathrm{E} 8$ \\
& & & & & \\
Agriculture & 20.907 & 10728.109 & .000 & .998 & $1.202 \mathrm{E} 9$ \\
Education & & & 5.027 & .170 & \\
Illiterate & 18.871 & 28420.969 & .000 & .999 & $1.568 \mathrm{E} 8$ \\
Primary & 19.123 & 28420.969 & .000 & .999 & $2.018 \mathrm{E} 8$ \\
Secondary & 19.938 & 28420.969 & .000 & .999 & $4.561 \mathrm{E} 8$ \\
Age of mother & .036 & .048 & .556 & .456 & 1.036 \\
Constant & -40.871 & 49225.788 & .000 & .999 & .000 \\
\hline
\end{tabular}


Logistic regression analysis shows that the effects of leveled variables on sufficient breast feeding in which only type of family has significant influence (Table V).

\section{Discussion}

The first year of an infant's life is the period of most rapid growth and an important nutrition transition, whereas poor infant feeding practices (IFP) directly or indirectly contribute to under nutrition, morbidity and mortality. The present study was done with a view to determine the characteristics of feeding practices and nutritional status of infants in selected villages at Dhamrai. It was found that $261(81.5 \%)$ of the mothers were from the age group of 20-30 years and their mean age was $25.34 \pm 4.281$ years. About half of the respondents $151(47.2 \%)$ had completed primary education and $96(30 \%)$ had secondary education. In Bangladesh, Mahejabin, et al. ${ }^{23}$ observed the same findings. Most of the respondents $301(94.1 \%)$ were housewives, $14(4.4 \%)$ were service holders and $5(1.6 \%)$ were agriculture workers. Haque and his collegues ${ }^{24}$ conducted a study in a selected peri urban area of Bangladesh where most of the mothers 307(98.4\%) were housewife. The mean monthly family income of the respondents was 7626.56 \pm 3171.248 Taka. This was quite high per capita income of Bangladesh. ${ }^{25}$ It might be due to location of study place and overall educational status of the respondents. More than 190(59.4\%) of the respondents were belonged to nuclear family and about 75 (23.4\%) of the mothers' BMI were $<18.5$ which is the cut off value for chronic energy deficiency /maternal malnutrition. This observation is more close to Shaili (2012) study. ${ }^{26}$ Regarding age of infants, $137(42.8 \%)$ belongs to age group 9-12 months, among others $124(38.8 \%), 59(18.4 \%)$ of the respondents were 6-9 months and less than six month of age group respectively. Near about one third infants were more than $8 \mathrm{~kg}$ and 95(29.7\%) were $6-8 \mathrm{~kg}$ and $53(16.6 \%)$ were less than $4 \mathrm{~kg}$. The study found that 284(88.8\%) newborns were breastfed and were given colostrums as first fed which was similar to that of results of NDHS 2011. ${ }^{27}$ The few difficulties faced by mothers for exclusive breast feeding in the current study were ignorance, illness and insufficient breast milk. These findings were more or less similar with findings conducted by Awogbenja, et al1 ${ }^{4}$ in Nasarawa state, North Central Nigeria, where the dominant reasons are mother's health, child's refusal to suck and tradition / culture. Another study conducted in Morogoro Municipality in Tanzania, where eight percent of the mothers discarded colostrum on the account that it was not good for their neonates. ${ }^{28}$ Fifty percent mothers started complementary feeding after six months' completion of age and only $27(9.7 \%)$ at four months of age. This finding is in conformity with the findings of Meshram and co-workers which established that about $57 \%$ children of 6-11 months old received complementary feeding in rural Madhya Pradesh. ${ }^{29}$ The common types of complementary food were khichuri (49.7\%), shagu/suji (21.5\%), fruit juice $(6.8 \%)$ given as family food. Haque, et al. ${ }^{30}$ conducted a study where the results show that the common weaning food were suji $(43.5 \%)$, khichuri $(36.1 \%)$, boiled eggs $(25.6 \%)$ and fruit juice $(24.4 \%)$ which was more or less similar to the study. In the present study 208(65\%) mothers were encouraged by doctors to practice weaning food for children, while $64(20 \%)$ encouraged by their relatives. This goes in line with results from Netrakona district Bangladesh; where the doctor mainly encouraged the mothers for practicing weaning food for their babies. ${ }^{31}$ The prevalence of severe underweight and moderate underweight in the studied children were $10.9 \%$ and $14.1 \%$ respectively, the prevalence of moderate and severe wasting children was $6.2 \%$ and $3.2 \%$ respectively and the prevalence of severely and moderately stunted children were $8.3 \%$ and $10.9 \%$ respectively. The findings of Safari, Kimambo and Lwelamira ${ }^{28}$ are in the agreement with the present study. Logistic regression analysis shows that the effects of leveled variables on sufficient breast feeding in which only type of family has significant influence.

Thus it can be concluded from the results that breast feeding was popular in rural women though their knowledge about the same needs should be improved. As their perceptions regarding the feeding practices directly influence the health of the infant therefore false beliefs and myths attached to infant's feeding deeply rooted in all strata of community need to be replaced. 


\section{References}

1. Nkala TE and Msuya SE. Prevalence and predictors of exclusive breastfeeding among women in Kigoma region, Western Tanzania: a community based crosssectional study. International Breastfeeding Journal $2011 ; 6(17)$.

2. Hanif HM. Trends in breastfeeding and complementary feeding practices in Pakistan 19902007. International Breastfeeding Journal 2011; 6(15).

3. Kumar D, Goel NK, Mittal PC, Misra P. Influence of infant-feeding practice on nutritional status of underfive children. Indian Journal of Paediatrics 2006 73:417-22.

4. Kimani-Murage EW, et al. Patterns and determinants of breastfeeding and complementary feeding practices in urban informal settlements. BMC Public Health $2011 ; 11: 396$.

5. Waiswa P, Peterson S, Tomson G, Pariyo GW. Poor newborn care practices - a population based survey in eastern Uganda. BMC Pregnancy Childbirth 2010; 10:9.

6. Agudo YC, Jones AD, Berti PR, Macias SL. Breastfeeding, complementary feeding practices and childhood malnutrition in the Bolivien Andes. Archivos Latinoamericanos de Nutricion 2010; 60(1):7-14.

7. Dibley MJ, Senarath U, Agho KE. Infant and young child feeding indicators across nine East and Southeast Asian countries: an analysis of National Survey Data 2000-2005. Public Health Nutrition 2010; 13(9):1296-1303.

8. The World Health Organization, Infant and Young Child Feeding, World Health Organization, Lyon, France, 2009.

9. $\mathrm{Ku} \mathrm{C}$ and Chow SKY. Factors influencing the practice of exclusive breastfeeding among Hong Kong Chinese women: a questionnaire survey. Journal of Clinical Nursing 2010; 19 (17-18): 243445.

10. Inayati DA, et al. Infant feeding practices among mildly wasted children: a retrospective study on Nias Island, Indonesia. International Breastfeeding Journal 2012, 7:3.

11. Jones G, Stekete RW, Black RE, Bhutta ZA, Morris SS. Bellagio Child Survival Study Group: How many child deaths can we prevent this year? The Lancet 2003: 362:65-71.
12. World Health Organization: Infant and young child feeding. [http://www. wpro.who.int/internet/ resourc es.ashx/CHD/docs/IYCF_model_web.pdf].

13. Breastfeeding Promotion Network India (BPNI): Faulty feeding practices and malnutrition. Available from: http://www.bpni.org/Article/faultyfeeding.asp.

14. Awogbenja, Dehinde M. and Fabian U. Feeding Practices and Nutritional Status of Under- Five Children in Nasarawa State, Nigeria. PAT J 2010; 6 (1):23-35

15. Beattie J, Carachi R. Practical Paediatric Problems. 1st ed. Hodder Arnold; London: 2005; 341-343.

16. Cherop CE, Keverenge-Ettyang AG, and Mbagaya GM. Barriers to exclusive breastfeeding among infants aged 0-6 months in Eldoret municipality, Kenya. East African Journal of Public Health 2009; 6(1): 69-72.

17. Thurman SE and Allen PJ. Integrating lactation consultants into primary health care services: are lactation consultants affecting breastfeeding success? Pediatric Nursing 2008; 34(5): 419-25.

18. Mitra SN, Al-Sabir A, Saha T, Kumal S. Bangladesh Demographic and Health Survey 1999-2000. Dhaka, Bangladesh and Calverton, USA: National institute of population research and training, Mitra and Associates, and ORC Macro; 2001.

19. Mitra SN, Ali MN, Islam S, Cross AR, Saha T. Bangladesh Demographic and Health Survey, 19931994. Calverton, USA: National institute of population research and training, Mitra and Associates, and Macro International Inc; 1994.

20. National institute of population research and training (NIPORT): Bangladesh demography and health survey 2011. Dhaka, Bangladesh and Calverton, USA: NIPORT, Mitra and Associates, and ORC Macro; 2005.

21. National institute of population research and training (NIPORT): Bangladesh demography and health survey 2007. Dhaka, Bangladesh and Calverton, USA: NIPORT, Mitra and Associates, and Macro International; 2009.

22. National institute of population research and training (NIPORT): Bangladesh demography and health survey 2011. Dhaka, Bangladesh and Calverton, USA: NIPORT, Mitra and Associates, and ICF International; 2013. 
23. Mahejabin F, Khan AW, Sultana M. Sociodemographic characteristics of the mothers and infant feeding practices in some semi urban villages of a selected Upazilla, Community Based Medical Journal 2013; 2(1):43-48.

24. Haque A, et al. Characteristics of Breastfeeding and Complementary Feedings Practices among the under two Children with their Nutritional status in a selected Periurban area of Bangladesh. ICMH Journal 2013; 3(2): 77-81.

25. Bangladesh Bureau of statistics, 2013.

26. Shaili V, et al. A Community Based Study on Breastfeeding Practices in a Rural area of Uttarakhand; National Journal of Community Medicine 2012;3(2)

27. Ministry of Health and Population USAID, ICF Macro, New ERA. Nepal Demographic and Health Survey 2011-2012.
28. Safari JG, Kimambo SC and Lwelamira JE. Feeding practices and nutritional status of infants in Morogoro Municipality, Tanzania; Tanzania Journal of Health Research, 2013; 15(3).

29. Meshram II, Kodavanti MR, Chitty GR. Influence of Feeding Practices and Associated Factors on the Nutritional Status of Infants in Rural Areas of Madhya Pradesh State, India. Asia Pac J Public Health 2013

30. Haque MJ, et al. Infant Feeding Practice by the Rural Mothers of Dinajpur District. Dinajpur Med Col J 2010; 3 (1):35-38.

31. Uddin MB, Rahman SMB and Hussain I. Infants Feeding Practices among Garo and non Garo Mothers from Netrakona District Bangladesh. World Journal of Medical Sciences 2011: 6 (4): 202-08. 